\title{
ANÁLISE PESTEL APLICADA AO NÚCLEO DE ARTE E CULTURA INDÍGENA DE BARCELOS-NACIB, EM BARCELOS - AM
}

\section{ARTIGO ORIGINAL}

GUIMARÃES JUNIOR, José Carlos ${ }^{1}$

GUIMARÃES JUNIOR, José Carlos. Análise PESTEL aplicada ao núcleo de arte e cultura indígena de Barcelos-NACIB, em Barcelos - AM. Revista Científica Multidisciplinar Núcleo do Conhecimento. Ano 06, Ed. 07, Vol. 08, pp. 100-111. Julho de 2021. ISSN: 2448-0959, Link de acesso: https://www.nucleodoconhecimento.com.br/administracao/cultura-indigena, $\quad$ DOI: 10.32749/nucleodoconhecimento.com.br/administracao/cultura-indigena

\section{RESUMO}

Esse artigo visou caracterizar o Núcleo de Arte e Cultura de Barcelos-NACIB, a importância da participação dessa entidade na economia local, bem como a apresentação de cenários para a melhoria da atividade de produção de artesanato após o período de pandemia do novo Coronavírus. Dessa forma, utilizou-se a ferramenta de análise PESTEL como prospecção de cenários nos ambientes PolíticoLegal, Econômico, Sociocultural, Tecnológico e ambiental, de modo a avaliar o ambiente externo. Espera-se que haja uma volta as atividades rotineiras a partir do momento que todos seus integrantes estejam imunizados, oferecendo assim, uma maior segurança aos seus integrantes, promovendo assim o crescimento continuado, porém ainda estamos em um ritmo lento no que se refere ao processo de imunização de toda a população do Brasil.

Palavras-chave: Análise Pestel, Nacib, Barcelos-AM.

\footnotetext{
${ }^{1}$ Doutor; Mestre; Especialista e Bacharel em Administração.
} 


\section{INTRODUÇÃO}

A análise PESTEL é uma é uma ferramenta que analisa os momentos políticos, econômicos, tecnológicos, sociais, ambientais e legais, onde utiliza-se em função da compreensão do cenário regional em mundial, buscando a identificação dos fatores micro e macro ambientais que impactam em todas as relações, e assim busca-se planejar as estratégicas para o bem desempenho do negócio.

Aguilar (1967), define a análise PESTEL como uma das ferramentas estratégicas mais difundidas para condução de análise de ambiente, que orienta a análise das dimensões Política, Econômica, Sociocultural, Tecnológica, Ambiental e Legal. Ela serve como ferramenta para o entendimento e análise do ambiente externo sistêmico, auxiliando em eventuais decisões para atividades organizacionais.

Segundo Ho Joseph (2014), a análise PESTEL não apenas o ambiente organizacional isolado, mas analisa também investiga também variáveis sociais e físicas, no que se refere a estrutura organizacional que são externos a ambiente organizacional, e dessa forma, no processo de produção das biojóias, identificando as relações entre todos os atores, bem como suas relações com o mercado de artesanato na região e no Brasil, frente a outros fornecedores e aos comerciantes no mercado como um todo.

A análise PESTEL, aplicada nesse artigo, é um alindamento da análise PEST[2], que significa Político, Econômico, Social e Tecnológico. Porém, com a evolução desta, foi incluída a parte legal e ambiental passando a ser conhecida como PESTEL.

Gupta (2013), "para além disso a sua aplicação é muito genérica no seu fundamento, criando dificuldades em perceber quais as regras a estabelecer quando nos deparamos com circunstâncias variáveis numa aplicação prática".

Sendo assim, empresas, organizações e associações, em uma análise global esparges, terão que realizar diferentes análises PESTEL, levando-se em 
consideração cada uma microrregião onde a referida organização esteja inserida, sem deixar de promover a análise em nível global, levando-se em consideração que cada região geográfica que esteja analisando, tem suas características regionais particulares, bem como toda sua evolução sociocultural.

Para Johnson; Scholes e Whittington (2005), quando as organizações usam a análise PESTEL, fica mais fácil perceber e identificar os principais indicadores de mudanças e conflitos, pelos meios políticos, econômicos, sociais, tecnológicos, ambientais (ecológicos) e jurídicos. Dados esses que, ao gerar os indicadores, poderão ser utilizados na construção de cenários futuros proporcionando sucesso ou fracasso das estratégias de uma organização ou programa governamental.

Todas estas circunstâncias externas e indiretas têm capacidade para influenciar a capacidade da empresa em produzir valor e, neste sentido, a análise PEST serve como uma "fotografia panorâmica" que ajuda a empresa a compreender e avaliar melhor todo o seu ambiente externo (GUO e NUNES, 2007).

Assim, o uso dessa ferramenta buscou a identificação dos fatores externos e macro ambientais que atuam na cadeia produtiva da piaçava e nas atividades do NACIB, buscando a promoção da inter-relação entre 0 processo de produção e comercialização do artesanato, agrupando essas variáveis em fatores, políticos, econômicos, sociais, tecnológicos e ambientais e legais.

Ainda comentando sobre o conceito da análise PESTEL, Ribeiro (2016) esses autores citam que "representa o ponto de partida para a análise das influências ambientais importantes no passado, e potenciais mudanças a ocorrer no presente com repercussões no futuro da organização e dos seus concorrentes.".

A aplicação desta ferramenta, portanto, deu-se pela análise política, econômica, social, tecnológica, ambiental e legal (jurídica), promovendo um aspecto amplo, buscando a otimização e utilização da ferramenta disposta.

Essa pesquisa se justifica pela necessidade de conhecer melhor o negócio do setor de artesanato do NACIB, analisando as variáveis que influenciam o processo de 
produção e comercialização das biojóias, além de oferecer alternativas para a alavancagem nas vendas, promovendo dessa forma, um melhor posicionamento no mercado de biojóias, no Brasil e no mundo.

\section{METODOLOGIA}

Essa pesquisa é de natureza pura por buscar gerar novos conhecimentos acerca das atividades desenvolvidas no âmbito do Núcleo de Arte e Cultura Indígena de BarcelosNACIB, e desta forma foi possível explorar o tema ainda pouco conhecido, o qual compreende às atividades desempenhadas por esses atores no município de Barcelos. Assim foram empreendidos esforços para a descrição das ações e explicação dos fatores determinantes com efeitos significativos das atividades.

Como procedimentos técnicos, a pesquisa se baseou em bibliografias e documentos produzidos sobre artesanato no Brasil e no estado do Amazonas, portanto, utilizando dados secundários, informações essas que permitiram realizar um estudo de caso do Núcleo de Arte e Cultura Indígena de Barcelos (NACIB), utilizando-se de pesquisa de campo com todos os integrantes dessa Associação, gerando informações primárias, e assim trata-se de uma pesquisa sem qualitativa por analisar informações não mensuráveis, ao mesmo tempo em que gera dados quantitativos.

\section{CARACATERIZAÇÃO DO NACIB}

O NACIB foi criado em 2012, a partir da reunião de alguns representantes indígenas do município de Barcelos - AM, que, preocupados com a manutenção da sua cultura e dos conhecimentos tradicionais para gerações futuras, desejavam criar uma Entidade de forma a promover atividades relacionadas ao artesanato.

A ideia, estruturada pela coordenadora-geral Dinalva Campos, era de representar os artesãos, agricultores e demais trabalhadores indígenas, buscando parcerias por meio de inserção no mercado e da divulgação dos trabalhos de artesanato. O NACIB foi constituído por 20 integrantes ativos em sua organização, os quais atuam de maneira 
muito influente na atividade de produção de artesanato com produtos da floresta e são referência na produção de biojóias em toda a região.

Núcleo de Arte e Cultura Indígena de Barcelos - As condições de trabalho dos artesãos na associação são razoáveis, apesar do fato de não terem uma sede própria, os encontros ocorrem sempre na residência de um dos integrantes, uma vez por mês, aos finais de semana ou quando da realização de algum evento. Acontecendo as oportunidades, os integrantes da associação expõem seus produtos no Mercado Municipal de Barcelos e, aos finais de semana, em barracas na praça central da cidade, ou ainda ao lado do aeroporto municipal, principalmente na temporada de pesca esportiva, que ocorre entre os meses de julho a dezembro.

Para o desenvolvimento deste trabalho, foi necessário observar as práticas rotineiras da cadeia da piaçava e a produção de artesanato pelos integrantes do NACIB na busca da matéria-prima na floresta, como os cipós e a piaçava, utilizados na confecção de cestarias e biojóias, e no processo de construção de oportunidades econômicas, sob a ótica de um produto que tem uma matéria-prima originária da biodiversidade. (GUIMARÃES JUNIOR, 2021).

A busca incipiente que este artigo se baseou refere-se à construção de elementos referenciais que incitem a reflexão da sociedade acerca da realidade de vida amazônica sobre os gargalos existentes para a promoção do desenvolvimento local e da economia regional, sob a ótica dos artesãos do NACIB.

Dessa forma estabeleceu-se a divisão deste trabalho, considerando os marcos da construção do pensamento de forma dialética, tanto no diálogo com os entrevistados e com os atores da cadeia produtiva, representado pelos artesãos do NACIB, quanto oferecendo conceitos e informações oportunas para a melhor compreensão dessa realidade.

Assim torna-se importante a identificação do contexto da atividade em desacordo acerca das regras impostas aos artesãos do NACIB, procurando entender as posições dos atores; os argumentos que são defendidos e criticados durante os conflitos; a 
evolução dos debates em torno de prováveis mudanças de comportamento, e quais deverão ser os caminhos trilhados por esses atores. Além disso, destaca-se a importância das atividades desenvolvidas pelo Núcleo de Arte e Cultura Indígena (NAClB), organização que desenvolve atividades de produção de artesanato, cuja matéria-prima é a piaçava, sob a perspectiva da Análise PESTEL. Dessa forma e no sentido de evidenciar essa importância, elaborou-se o gráfico (1), abaixo, onde apresenta as atividades desenvolvidas em Barcelos, com seus respectivos percentuais de importância de participação na geração de receitas para o município.

Gráfico 1 - Atividades econômicas em Barcelos - AM.

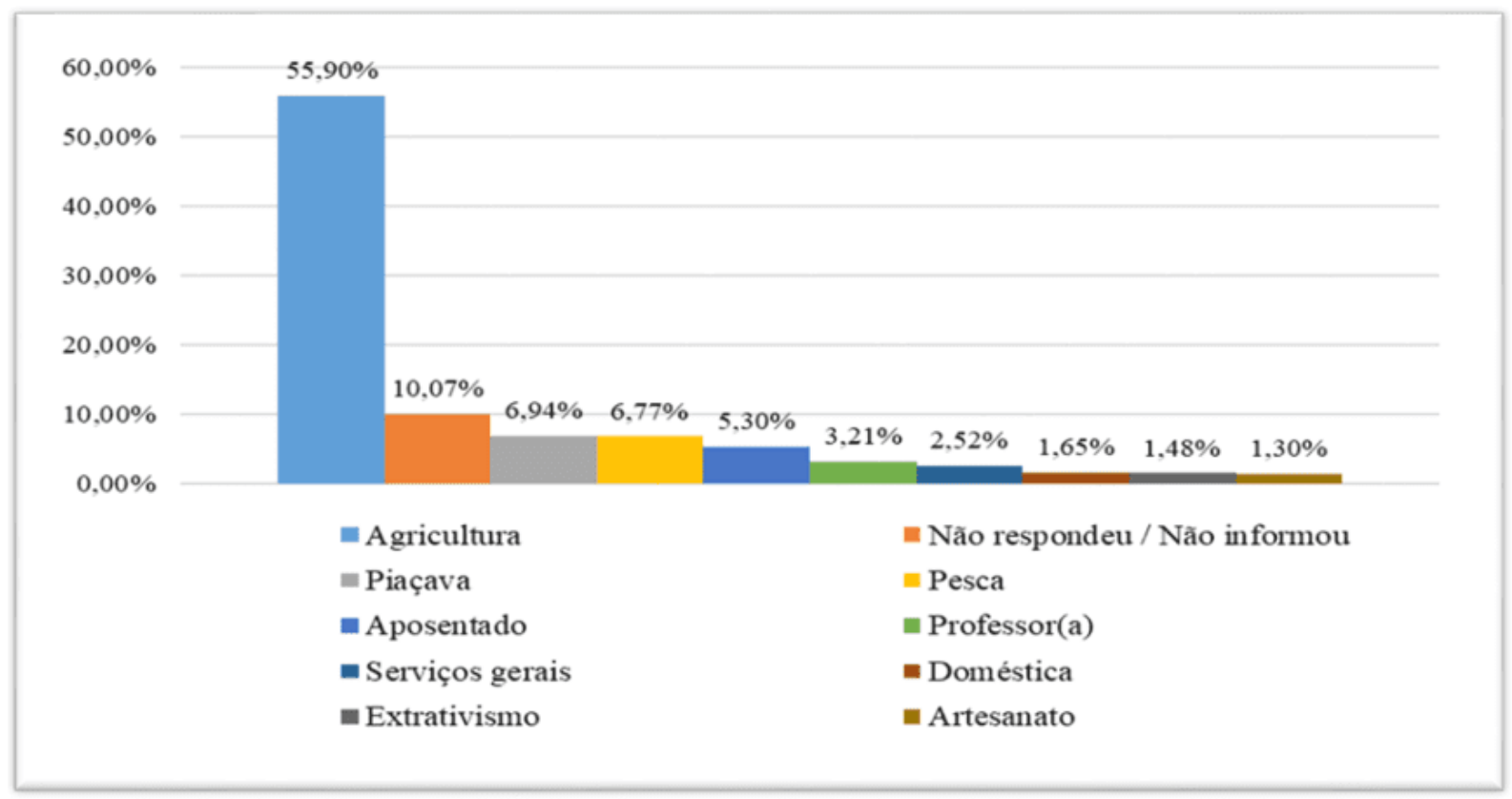

Fonte: Elaboração própria, com dados do Atlas Brasil (2010) e Instituto Socioambiental (ISA) (BARRA; DIAS, 2013).

A continuidade das práticas econômicas centradas no extrativismo para garantir o acesso a tais produtos resultam na escassez e na redução localizada de vários recursos. Logo, o controle de acesso a esses bens naturais existentes dentro dos limites das comunidades, juntamente com a elaboração de regras que busquem a regulação da forma de exploração, além da definição de quem tem o direito de explorá-los, deve ser alternativa para melhor gerir os conflitos sociais, econômicos e ambientais latentes. 
Fez-se necessário promoveu-se a caracterização do NACIB, identificando-se e analisando-se as atividades dos artesãos, bem como as características sociais, econômicas e culturais dos integrantes, estimulando a discussão sobre os aspectos sociais e a capacidade que a atividade de produção de artesanato oferece aos integrantes para a geração e melhoria dos níveis socioeconômicos dos artesãos.

O estudo de caso do NACIB é decorrente de sua importância por agregar artesãos que detêm o conhecimento tradicional na confecção de artesanato, tendo a piaçava com base da matéria-prima, além das sementes retiradas da floresta. Os entrevistados foram os atores que se dispuseram a participar da pesquisa e que atuam como extrativistas, os intermediários na comercialização da fibra, e os artesãos do NACIB.

Através dos dados obtidos na aplicação do questionário e das observações realizadas principalmente no que se refere as atividades de produção do artesanato pelo artesãos do NACIB, segmentamos em seis categorias diferentes as variáveis, são elas: políticas, econômicas, sociais, tecnológicas, Ambientais e Legais (jurídicas); sendo que para cada um deles são mencionados um ou mais variáveis e de que maneira cada um deles pode afetar a empresa e o seu lucro (tanto positivamente como negativamente), e assim, elaboramos o Quadro (1), para melhor explicitar a análise PESTEL na cadeia produtiva da piaçava e do NACIB.

QUADRO 1: Variáveis e Cenários - Análise da Produção de Artesanato

\begin{tabular}{|l|l|}
\hline Variáveis & Cenários \\
\hline Políticos & $\begin{array}{l}\text { - Fatores políticos são fundamentais, pois os comerciantes da fibra, } \\
\text { de artesanato pelo NACIB, pois ambos precisam de estabilidade } \\
\text { política para dar continuidade as suas operações. }\end{array}$ \\
\hline - No que se refere a produção de artesanato pelos artesãos do \\
\hline Socioculturais & NACIB; já evidenciamos através das respostas obtidas quando da \\
\hline
\end{tabular}




\begin{tabular}{|c|c|}
\hline & $\begin{array}{l}\text { aplicação de questionário, diversas situações socioeconômicas que } \\
\text { refletem a situação desses profissionais. } \\
\text { - Em análise geral, podemos informar que todos os integrantes } \\
\text { possuem uma mesma origem indígena, porém com etnias } \\
\text { diferentes, mas que suas culturas não afetam as relações de } \\
\text { trabalho na produção de artesanato, portanto não influenciando nas } \\
\text { suas forças de trabalho. }\end{array}$ \\
\hline Tecnológicos & $\begin{array}{l}\text { - No que se refere a produção de artesanato, em hipótese alguma } \\
\text { os artesãos têm interesse em inserir no processo de produção de } \\
\text { artesanato, alguma espécie de tecnologia que possa oferecer uma } \\
\text { maior produção das peças. }\end{array}$ \\
\hline Ambientais & $\begin{array}{l}\text { - Quanto a produção de artesanato, a preocupação crescente sobre } \\
\text { o tema meio ambiente entre todos os países, onde os consumidores } \\
\text { buscam produtos de empresas que produzam seus produtos com } \\
\text { responsabilidade ambiental e socialmente eficaz, valorizando dessa } \\
\text { forma, os conhecimentos tradicionais expressos nas peças de } \\
\text { artesanato. } \\
\text { - Essa demanda tem se tornado mais importante devido à crescente } \\
\text { escassez de matérias-primas além do uso de matérias primas } \\
\text { originárias da floresta. }\end{array}$ \\
\hline Legais & $\begin{array}{l}\text { - Quanto ao NACIB, até o ano de } 2012 \text {, a Associação não tinha o } \\
\text { registro na Junta Comercial do Estado do Amazonas, situação } \\
\text { evitava diversas oportunidades de negócios com outras empresas } \\
\text { e comerciantes que precisam de nota fiscal para que pudessem } \\
\text { adquirir seus produtos e promover o transporte de maneira formal. } \\
\text { - A partir desse ano (2012), as oportunidades de mercado para o } \\
\text { NACIB, tem surgido inúmeras outras oportunidades de negócios } \\
\text { que já foram captadas e efetivadas, além de dar condição a }\end{array}$ \\
\hline
\end{tabular}


Associação e seus integrantes de terem acesso alinhas de créditos e políticas públicas.

- A implementação do processo de exportação dos seus artesanatos, já está em estágio avançado, onde em um primeiro momento será o desenvolvimento de um aplicativo que terá todas as suas peças de artesanato a disposição dos clientes.

Fonte: Autor, 2021

Os fatores evidenciados na Análise PESTEL devem ser compreendidos pelos artesãos do NACIB, como uma ferramenta de planejamento estratégico para aprimorarem as relações da cadeia produtiva, bem como aperfeiçoamento do processo de comercialização das biojóias de artesanato.

Na utilização da ferramenta PESTEL, na análise do Núcleo de Arte e Cultura Indígena de Barcelos-NACIB, no que se refere a suas formas de governanças, foi possível a realização do diagnóstico das ações que incorrem do desenvolvimento das atividades.

Dentre os principais resultados dessa pesquisa, ressalta-se o fato de que as análises referentes as atividades do processo produtivo do artesanato, e levando-se em conta todos os atores atuam nessa atividade, deve-se ter cuidado na propositura de ações que interfiram no processo já existente, tendo em vista que, a realidade regional e especificamente dessa atividade, não permite mudanças radicais sem que todo um planejamento estratégico onde políticas públicas eficientes e eficazes definitivamente alcancem todos esses atores.

Não se pode ignorar os obstáculos existentes no dia a dia dessa atividade, visto que as ações dos órgãos públicos, seja na forma de oferta de políticas públicas ou de melhores condições para que os extrativistas possam sobreviver dessa atividade, estão muito aquém do que foi identificado durante a realização da pesquisa. Essas novas estratégias devem ser utilizadas frente as ameaças existentes de uma boa 
relação na cadeia produtiva, proporcionando boas oportunidades de crescimentos para todos os integrantes da cadeia.

No que se refere ao Núcleo de Arte e Cultura Indígena da Barcelos - NACIB, a identificação da realidade existente nas relações internas entre os artesãos e os processos de comercialização de biojóias foi importante no sentido de que a propositura das mudanças nessas relações, devem ser muito bem estruturadas e colocadas em prática de forma incrementais sem que a cultura e os hábitos identificados sofram algum tipo de mudança a ponto de provocar alguma forma de desentendimento entre seus integrantes.

Deve-se, portanto, promover uma avaliação periódica nas relações internas de seus integrantes, bem como o posicionamento do NACIB no mercado de artesanato.

\section{CONSIDERAÇÕES FINAIS}

O Núcleo de Arte e Cultura Indígena de Barcelos-NACIB, é uma Associação de Artesãos que mantém um papel associado de muita relevância, pois proporciona uma maior agregação entre os seus integrantes, e é uma Associação orientadora das negociações realizadas por esse grupo com comerciantes locais e empresas de outros estados.

Nas análises realizadas durante as fases da pesquisa e utilizando-se a coerência, observou diversos conflitos existentes na cadeia produtiva da piaçava entre os diversos atores que integram essa relação, que muitas vezes são provocadas por interesses econômicos e de sobrevivência por parte dos extrativistas.

Em uma análise do NACIB, não é diferente, pois seus integrantes, mesmo organizados, avistam interesses difusos no que se refere aos interesses individuais.

O coordenador do NACIB é a pessoa que assume todas as responsabilidades da Associação, orienta seus integrantes desde as melhores práticas para se buscar a matéria prima para a confecção do artesanato na floresta, seja o cipó, a piaçava ou 
sementes, define os papéis de cada integrante e toma das decisões necessárias para que a atividade possa sempre progredir.

Assim, é possível identificar que a figura do coordenador eleito, é de uma liderança nata, que conta com o apoio e respeito de todos os integrantes e das demais pessoas que interagem com a Associação, e essa liderança é reconhecida de forma muito perceptível quando se conversa com moradores e comerciantes da cidade de Barcelos, além de alguns representantes de órgãos, o Sebrae por exemplo.

A cadeia produtiva da piaçava oferece uma relação comercial de grande destaque social e comercial, social e ambiental em todo o município, onde toda a produção é atendida pelo processo de extrativismo, geradora de renda para todos os atores envolvidos na atividade, fornecendo matéria prima original para a produção de artesanato pelos artesão, sem que ocorra nenhum tipo de conflito, seja pela quantidade adquirida dos comerciantes da fibra, seja pelas origens de seus integrantes, fato esse que poderia, de alguma forma, promover algum tipo de conflitos no que se refere as suas culturas incidindo no processo de confecção das peças de artesanato.

\section{RECOMENDAÇÕES}

O NACIB já tem vários comerciantes interessados e compradores dos seus produtos, porém necessita de maior articulação para poder se organizar administrativamente, no sentido de desenvolver estratégicas que possam levar seus produtos a lugares mais distantes, seja no mercado nacional e internacional principalmente, onde a aceitação, já identificada, foi muito positiva. Para que a ação de atingir mercados internacionais seja coberta de êxito, precisa articular com maior eficácia todo o processo de produção, tendo em vista a terem determinadas quantidade de peças em estoque para que não venham a faltar, em caso de um grande pedido.

Necessário, portanto, refletir a respeito de um plano de negócio para essa atividade, o que pode ser conseguido através da incubação da associação em entidades que 
oferecem essa oferta de serviços, seja na Universidade do Estado do Amazonas, ou na Universidade Federal do Amazonas, por exemplo.

Nessas instituições são oferecidos, com uma certa regularidade, editais para captação de novas incubadas, no caso o NACIB, onde serão oferecidos uma série de novos conhecimentos e elementos importantes para serem aprendidos e incrementados para o negócio de produção de artesanato; esses elementos são expressos em logomarca, ações de marketing, dente outras.

Importante verificar as potencialidades de melhoria e aprimoramento da comercialização do artesanato produzido pelo $\mathrm{NACIB}$, tendo em vista que na aplicação do questionário, identificou-se que a atividade, para a maioria dos seus integrantes, promoveu uma melhoria significativa nas suas receitas e uma oferta de melhor condição de vida para os filhos desses artesãos.

Assim, o aprimoramento no processo organizacional do NACIB oferecerá melhores condições para a prospecção de novos mercados que sejam capazes de aceitar seus produtos, além de parcerias que estimulem um aumento na produção de artesanato.

Finalmente destaca-se a existência de vantagem competitiva da propositura de mudanças na governança dessas atividades, sendo assim, uma constante avaliação desses processos é importante para que a estratégica possa ser desenvolvida, oferecendo melhorias em ambos os processos e aos seus integrantes.

\section{REFERÊNCIAS}

AGUILAR, F. J. Scanning the Business Environment. The Macmillan Company, 1967

ATLAS BRASIL, 2010, disponível em www.atlasbrasil.org.br, acesso em 9 de maio de 2021. Disponível em: http://www.atlasbrasil.org.br/

GUO, C.; NUNES, M.B. Using PEST Analysis as a Tool for Refining and Focusing Contexts for Information Systems. 6th European Conference on Research 
Methodology ofr Business and Management Studies. Lisbon, Portugal, pp 229-236, July 9-10, 2007.

GUIMARAES JUNIOR, José Carlos- 0 extrativismo da piaçava (Leopoldinia Piassaba Wallace) no município de Barcelos-AM/José Carlos Guimarães Junior. Manaus (AM): [s.n.],2021- 88p.:.;color;30cm

GUPTA, A. Environmetal and pest analisys: an approach to external business environmnet. Meirt Research Journal of Art, Social Sciences and Humanities, Vol 1 N.2 pp 13-17, 2013

ISA, 2013.

Disponível

em: https://acervo.socioambiental.org/sites/default/files/publications/0AL00033.pdf, acesso em maio de 2021.

JOHNSON G., Scholes K., Whittington R., (2005), "Exploring Corporate Strategy: text and cases", Seventh Edition, Upper Saddle River, NJ: Prentice Hall

JOSEPH, Ho (2014), "Formulation of a systemic PEST Analysis for Strategic Analysis", European Academic Research, Vol. 2, № 5, pp 6478-6492.

NACIB- Núcleo de Arte e Cultura Indígena de Barcelos, disponível em https://www.facebook.com/nacib.artindigena/, acesso em 25 de maio de 2021.

RIBEIRO, Renato Vieira. "Estratégia Empresarial E de Recursos Humanos". Ed. IESDE BRASIL SA, 2016.

\section{APÊNDICE - REFERÊNCIA DE NOTA DE RRODAPÉ}

2. "O acrônimo PEST é utilizado para identificar quatro dimensões de análise ambiental de natureza qualitativa de fenômenos dificilmente quantificáveis: a Política, a Econômica, a Social e a Tecnológica"

Enviado: Junho, 2021. 
Aprovado: Julho, 2021.

RC: 91605

Disponível em: https://www.nucleodoconhecimento.com.br/administracao/cultura-indigena 